\title{
Determination of bearing capacity of shallow foundations without using superp...
}

D Y Zhu; C F Lee; K T Law

Canadian Geotechnical Journal; Apr 2003; 40, 2; ProQuest Science Journals

pg. 450

\section{Determination of bearing capacity of shallow foundations without using superposition approximation}

\author{
D.Y. Zhu, C.F. Lee, and K.T. Law
}

\begin{abstract}
The Terzaghi superposition assumption has been widely used to determine the bearing capacity of shallow footings. Although this assumption always errs on the safe side, a rigorous procedure to calculate the bearing capacity is still of engineering value. This paper presents such a procedure that is free from errors as a result of the superposition assumption. It demonstrates that the ultimate bearing capacity can be precisely expressed by the Terzaghi equation, except that the bearing capacity factor $N_{\gamma}$ is dependent upon the surcharge ratio. A recently developed numerical method, i.e., the critical slip field method, is used to calculate the modification coefficient for modifying $N_{\gamma}$ It is found that this modification cocfficient increases with the surcharge ratio at small values of surcharge ratio and then remains constant for large values of surcharge ratio. However, the errors invoked by the superposition assumption do not exceed $10 \%$. On the basis of numerical calculations, a simple closed-form expression of the modification coefficient is proposed that yields the theoretically rigorous ultimate bearing capacity. In the later part of the paper, errors in bearing capacity calculations owing to the use of conventional procedures are analyzed. It is concluded that the continued use of conventional procedures is justified, but the inherent crrors should not be neglected in assessing the performance of shallow foundations.
\end{abstract}

Key words: shallow foundation, strip footing, ultimate bearing capacity, critical slip field.

Résumé : L'hypothèse de superposition de Terzaghi a été communément utilisée pour déterminer la capacité portante de scmelles superficielles. Quoique cette hypothèse donne toujours des erreurs du côté sécuritaire, unc procédure rigoureuse pour calculer la capacité portante demeure valable pour l'ingénieur. Cet article présente une tclle procédure qui est libre d'erreurs dues à l'hypothèse de superposition. Il démontre que la capacité portante ultime peut être expriméc de façon précise par l'équation de Terzaghi, sauf que le coefficient de capacité portante $N_{\gamma}$ est dépendant du rapport de surcharge. Une méthode numérique développée récemment, i.e., la méthode du champ de glissement critique, est utilisée pour calculer le coefficient de modification de $N_{\gamma}$ On trouve que ce coefficient de modification augmente avec le rapport de surcharge aux faibles valeurs du rapport de surcharge, et demeure ensuite constant pour les fortes valeurs du rapport de surcharge. Cependant, les erreurs invoquées par l'hypothèse de superposition ne dépassent pas $10 \%$. Sur la base des calculs numériques, on propose une expression simple exacte du coefficient de modification qui donne la capacité portante ultime théoriquement rigoureuse. Dans la dernière partie de l'article, on analyse les erreurs dans les calculs de capacité portante dues à l'utilisation des procédures conventionnclles. On conclut qu'il est justifié de continuer à utiliser les procédures conventionnelles, mais que les erreurs inhérentes ne devraient pas être négligées dans l'évaluation de la performance des fondations superficielles.

Mots clés : fondation superficielle, semelle filante, capacité portante ultime, champ de glissement critique.

[Traduit par la Rćdaction]

\section{Introduction}

The bearing capacity of shallow foundations is commonly calculated using the Terzaghi equation (Terzaghi 1943), which assumes that the ultimate bearing capacity is the sum of three terms owing to surcharge, cohesion, and the weight of the soil, respectively. In evaluating the three terms, most methods assume two different failure mechanisms: one

Reccived 5 June 2001. Accepted 10 October 2002. Published on the NRC Research Press Web sitc at http://cgj.nrc.ca on 1 April 2003.

D.Y. Zhu. Department of Civil Fngineering, Nanjing Enginecring Institute, Nanjing, 210007, China.

C.F. Lee. ${ }^{1}$ Department of Civil Engineering, The University of Hong Kong, Pokfulam Road, Hong Kong,

K.T. Law. Department of Civil and Environmental Engineering, Carleton University, Otlawa, ON K IS 5B6, Canada.

'Corresponding author (e-mail: leecf@hkucc.hku.hk). 
corresponding to a weightless $c-\phi$ soil ( $c$ and $\phi$ are the cohesion and internal friction angle of the soil, respectively) with a surcharge $q$, and the other corresponding to a cohesionless soil with weight but without surcharge. Their respective contributions to the bearing capacity are then minimized separately by finding the critical failure mechanisms and then superimposed onto each other (Das 1999). The first failure mechanism results in analytical solutions to the two bearing capacity factors due to surcharge and cohesion, respectively, while the second leads to a numerically approximate solution to the bearing capacity factor due to the soil weight. In reality, only one failure mechanism should occur under the ultimate loading condition, and all contributions to the bearing capacity should be associated with a consistent critical failure mechanism that minimizes the sum of these contributions. Therefore, the superposition assumption is approximate in nature, erring on the safe side, since the sum of the minimal components is less than or equal to the minimal sum.

Although the Terzaghi superposition assumption proves to be always on the conservative side, an understanding of the resultant errors is also of value from the engineering standpoint. A more rigorous solution could potentially provide insights on foundation behaviour (Sieffert and Bay-Gress 2000) and pinpoint the uncertainties associated with soil parameters and the calculation method itself. On the other hand, a normally conservative procedure could sometimes become unconservative when back-analyzed shear strength values are used to design other foundations on the same soils but under significantly different loading conditions and (or) with different dimensions.

Several previous studies have involved the direct computation of bearing capacity of footings without superposition of the three terms contributed by frictional angle, cohesion, and surcharge, respectively. The results thus obtained involve no errors due to the Terzaghi superposition assumption. In this regard, the method of characteristics has often been employed to compute the bearing capacity of footings (Lundgren and Mortensen 1953; Cox 1962; Sokolovskii 1965; Davis and Booker 1971; Bolton and Lau 1993; and Xiao et al. 1998). According to Davis and Booker (1971), between the limiting case of no body forces, i.e., the Prandtl solution, and the limiting case of no surcharge, the superposition assumption could yield errors of up to $30 \%$. Bolton and Lau (1993) also confirmed that the superposition assumption would always err on the safe side, by a margin of no more than 20\%. Xiao et al. (1998) proposed a rather complex empirical equation for the bearing capacity factor $N_{\gamma}$, to eliminate the error caused by the superposition assumption. Michalowski (1997) examined the influence of soil weight on bearing capacity using a limit analysis in the context of the upper bound theorem (Chen 1975). He demonstrated that the bearing capacity factor $N_{\gamma}$ due to soil weight would increase with an increase in the ratios $q / \gamma B$ and $c / \gamma B$ (where $q$ is the surcharge above the base level of the footing, $\gamma$ is the unit weight of the soil, and $B$ is the width of the footing).

The purpose of this paper is to determine rigorously the bearing capacity of shallow foundations without making the superposition assumption and to examine the errors that could be invoked by this assumption. For simplicity, shallow strip footings with central and vertical loading are considered. In the aforementioned studies, most investigators have employed Prandtl-like and Hill-like failure mechanisms to incorporate the effects of roughness and smoothness between the footing base and the soil underneath. However, the Hill-like failure mechanism rarely occurs in the field or in tests where base smoothness is artificially provided (Vesic 1975). Hence, only the Prandtl-like mechanism is considered in this paper.

Consider also an active wedge immediately under the footing and two symmetrical fans sliding sidewalys and upward to the ground surface. This active wedge is assumed to be inclined at an angle $45^{\circ}+\phi / 2$ to the horizontal. The same assumption was also made by most previous investigators (e.g., Meyerhof 1963; Vesic 1973; Bolton and Lau 1993; Michalowski 1997), and its validity has been confirmed experimentally (De Beer and Vesic 1958). The determination of the thrust forces between the active wedge and the sliding fan (the location of which is to be determined) is the key step in computing the bearing capacity. In this paper, a newly developed numerical method, called the critical slip field method (Zhu et al. 2001), is employed for this purpose. With this method, a series of critical slip surfaces, constituting a critical slip field, is determined by a numerical procedure that is based on the limit equilibrium method of slices and the principle of optimality (Bellman 1957). Studies have shown that this method can yield solutions of active or passive earth pressures, along with the locations of critical slip surfaces, that are as accurate as those from the method of characteristics (Zhu et al. 2001), albeit within the limit equilibrium context. The implementation of this method is rather straightforward in comparison to the method of characteristics. Therefore, this method deserves to be employed for solving the bearing capacity problem. Before doing so, let us first examine an equivalent relationship inherent in the problem of bearing capacity.

\section{Equivalence of bearing capacity problems}

The soil under the foundation is assumed to be a rigid plastic medium obeying the Mohr-Coulomb failure criterion as follows:

$$
\text { [1] } \sigma_{1}-\sigma_{3}=\left(\sigma_{1}+\sigma_{3}\right) \sin \phi+2 c \cos \phi
$$

where $\sigma_{1}$ and $\sigma_{3}$ are the major and minor stresses respectively. Equation [1] can be rewritten in the form

$$
\begin{aligned}
\left(\sigma_{1}+c \cot \phi\right)-\left(\sigma_{3}+c \cot \phi\right)= & \left(\sigma_{1}+c \cot \phi\right. \\
& \left.+\sigma_{3}+c \cot \phi\right) \sin \phi
\end{aligned}
$$

Equation [2] implies that the general $c-\phi$ soil can be regarded as cohsionless if a hydrostatic stress equal to $c \cdot c o t \phi$ is imposed everywhere within the failure region, as illustrated in Fig. 1.

For a strip footing subject to vertical and central loading, as shown in Fig. $2 a$, the bearing capacity is expressed by the Terzaghi equation as

$$
q_{\mathrm{u}}=q N_{\mathrm{q}}+c N_{\mathrm{c}}+\frac{1}{2} \gamma B N_{\mathrm{r}}{ }^{(a)}
$$


Fig. 1. Diagram of Mohr-Coulomb failure criterion. $\tau, \tau^{\prime}$ are shear stresses.

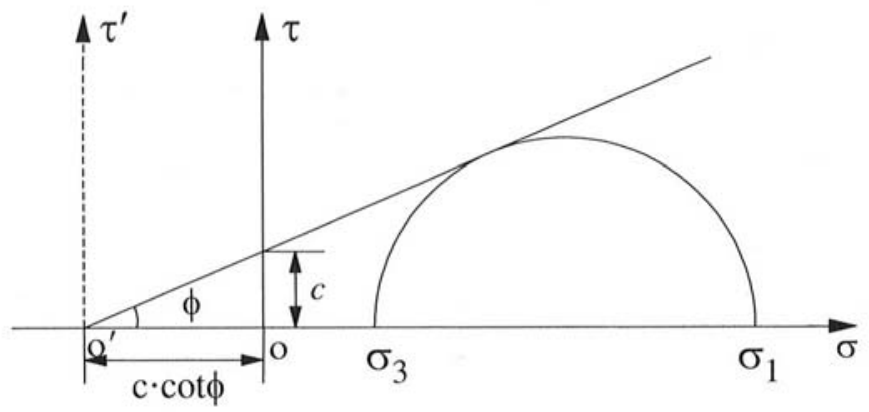

where $q_{\mathrm{u}}$ is the ultimate bearing capacity; $N_{\mathrm{c}}$ is the bearing capacity factor related to $c ; N_{\mathrm{q}}$ is the bearing capacity factor related to $q$; and $N_{\gamma}{ }^{(a)}$ is the bearing capacity factor related to $\gamma$. The superscript " $(a)$ " represents the case that is being considered. Bearing capacity factors $N_{\mathrm{q}}$ and $N_{\mathrm{c}}$ can be determined by analytical solutions, that is,

$$
N_{\mathrm{q}}=\tan ^{2}\left(\frac{\pi}{4}+\frac{\phi}{2}\right) \mathrm{e}^{\pi \tan \phi}
$$

$$
N_{c}=\left(N_{q}-1\right) \cot \phi
$$

In general, $N_{\gamma}^{(a)}$ should be dependent upon the following parameters of the soil and the footing: $\gamma, c, \phi$ and $B$. Now the soil underneath the footing is taken as a cohesionless material by imposing a uniform normal stress, $c \cdot \cot \phi$, on the surface of the footing and the soil, as shown in Fig. $2 b$. The bearing capacity can then be written as

$$
q_{\mathrm{u}}+c \cot \phi=(q+c \cot \phi) N_{\mathrm{q}}+\frac{1}{2} \gamma B N_{\gamma}^{(b)}
$$

where $N_{\gamma}{ }^{(b)}$ is dependent upon $q+c \cdot \cot \phi, \gamma$, and $B$.

The bearing capacity problem can be normalized by assuming unity in soil self-weight and in footing breadth, with the stress terms divided by $\gamma B$, as shown in Fig. $2 c$. The bearing capacity equation is rewritten as

$$
\frac{q_{\mathrm{u}}+c \cot \phi}{\gamma B}=\frac{q+c \cot \phi}{\gamma B} N_{\mathrm{q}}+\frac{1}{2} N_{\gamma}^{(c)}
$$

where $N_{\gamma}^{(c)}$ is dependent only upon the term $(q+c \cdot \cot \phi) / \gamma B$ as well as $\phi$. The term $(q+c \cdot \cot \phi) / \gamma B$ is referred to as the surcharge ratio $\lambda$, i.e.,

$$
\lambda=\frac{q+c \cot \phi}{\gamma B}
$$

By comparing eqs. [3], [6], and [7], it is found that

$$
N_{\gamma}^{(a)}=N_{\gamma}^{(b)}=N_{\gamma}^{(c)}=N_{\gamma}
$$

Therefore, the bearing capacity factor $N_{\gamma}$ in the Terzaghi equation is only dependent upon the surcharge ratio $\lambda$ for a specific value of $\phi$. The term $\left(q_{\mathrm{u}}+c \cdot \cot \phi\right) / \gamma B$ is defined as the normalized bearing capacity, $p_{u}$, i.e.,

$$
p_{\mathrm{u}}=\frac{q_{\mathrm{u}}+c \cot \phi}{\gamma B}
$$

Fig. 2. Equivalent bearing capacity problems. (a) Original problem with general soil and strip footing. $(b)$ Equivalent problem with cohesionless soil. $(c)$ Equivalent problem with cohesionless and unit-weight soil and unit-breadth footing.
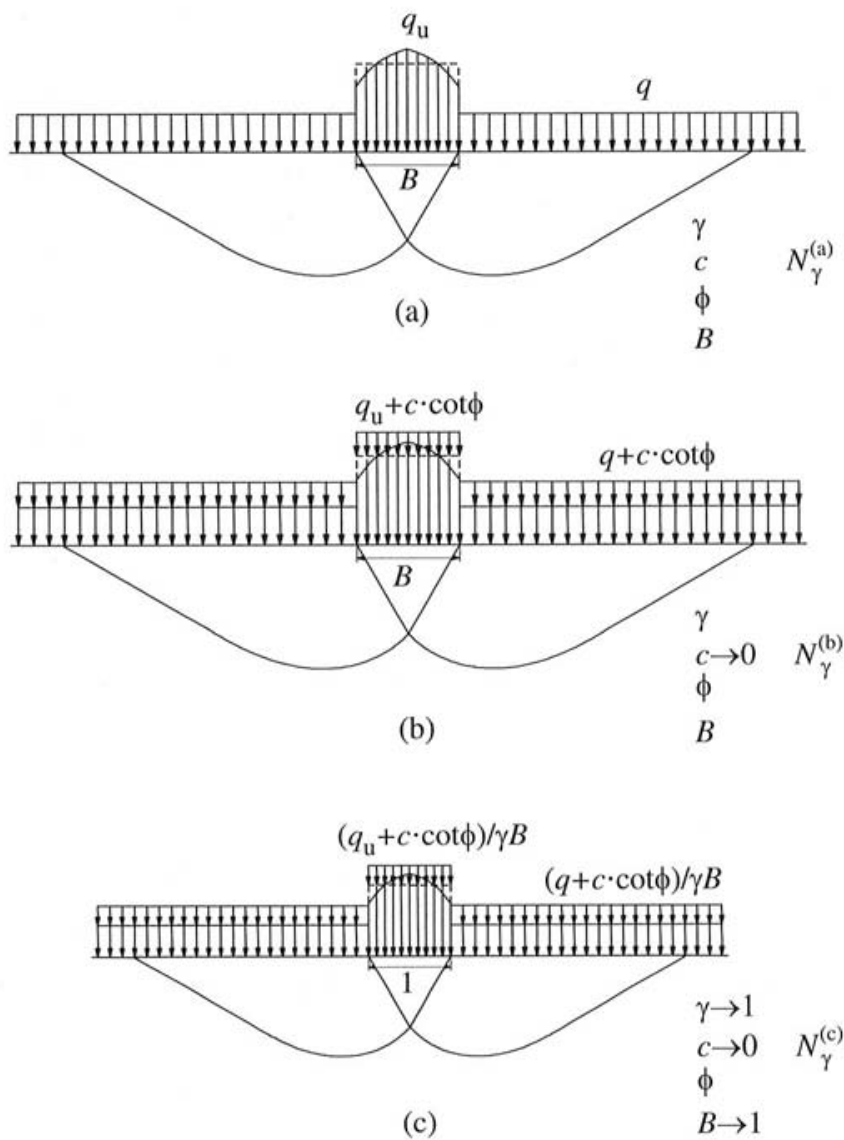

Equation [7] becomes

$$
\text { [10] } \quad p_{\mathrm{u}}=\lambda N_{\mathrm{q}}+\frac{1}{2} N_{\gamma}
$$

It should be noted that $N_{y}$, which is dependent upon $\lambda$, would be an integrated bearing capacity factor without involving the superposition approximation if a consistent failure mechanism is used to calculate the ultimate bearing capacity. Further, this equivalence holds under any vertical and central loading conditions, irrespective of the methods used to compute the bearing capacity.

\section{Bearing capacity determination without superposition approximation}

Consider a normalized situation of the bearing capacity problem, as shown in Fig. 3. The active wedge immediately underneath the footing is assumed to be inclined at an angle of $\pi / 4+\phi / 2$ to the horizontal. From eq. [10], $N_{\gamma}$ can be expressed as

[11] $N_{\gamma}=2 p_{\mathrm{u}}-2 \lambda N_{\mathrm{q}}$

For specific values of $\phi$ and $\lambda$, the normalized bearing capacity $p_{\mathrm{u}}$ is to be determined.

From the geometry of the footing and failure mechanism shown in Fig. 3, the weight of the active wedge is 
Fig. 3. Diagram for deriving the expression of $N_{\gamma}$

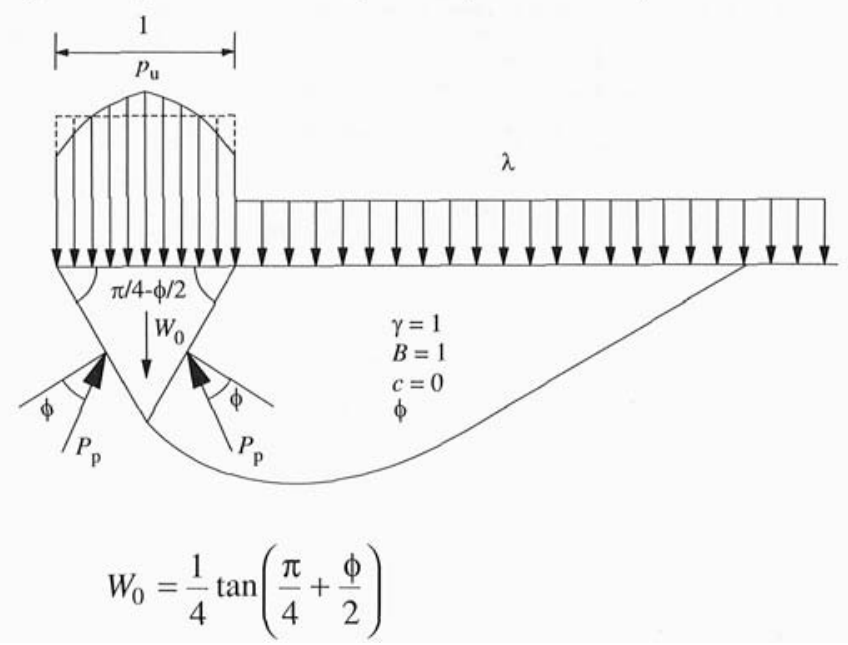

From vertical equilibrium of the active wedge, $p_{\mathbf{u}}$ is expressed as

$$
p_{\mathrm{u}}=2 P_{\mathrm{p}} \cos \left(\frac{\pi}{4}-\frac{\phi}{2}\right)-\frac{1}{4} \tan \left(\frac{\pi}{4}+\frac{\phi}{2}\right)
$$

where $P_{\mathrm{p}}$ is the passive earth force acting on the edges of the active wedge.

Substituting $P_{\mathrm{p}}$ from the above equation into eq. [11] results in

$$
N_{\gamma}=4 P_{\mathrm{p}} \cos \left(\frac{\pi}{4}-\frac{\phi}{2}\right)-\frac{1}{2} \tan \left(\frac{\pi}{4}+\frac{\phi}{2}\right)-2 \lambda N_{\mathrm{q}}
$$

Herein, the passive earth force $P_{\mathrm{p}}$ is calculated using the critical slip field method (Zhu et al. 2001). A typical example of the passive critical slip field is shown in Fig. 4.

It has been found that the location of the outermost passive critical failure surface moves outwards as $\lambda$ increases, as illustrated in Fig. 5. When $\lambda$ is too large, for example, with $\lambda=100$, the failure surface approaches the limit that is corresponding to the case of a weightless soil, or $\lambda=\infty$. However, in this situation, it can be seen from eq. [10] that the contribution of the term $N_{\gamma}$ to the ultimate bearing capacity is insignificant when compared to the term $\lambda N_{\mathrm{q}}$. Hence, the value of $N_{\gamma}$ thus computed using eq. [11] may not be accurate enough if small numerical errors exist in computing $p_{\mathrm{u}}$. This is inevitable for all numerical methods in common use. Fortunately, in this limiting case, there exists an analytical solution based on the theory of plasticity (Powrie 1997). For $\lambda \geq 100$, the soil can be regarded as weightless and the analytical slip surface is a combination of a $\log$-spiral and a straight line (sec Appendix A). A closed-form solution for computing $N_{\gamma}(\lambda=\infty)$ can thus be obtained using the limit equilibrium method, with the derivation given in Appendix A. Numerical values of $N_{\gamma}$ for $\lambda=0,0.01,0.1,1$, and 10 are computed using the critical slip field method. Values of $N_{\gamma}$ for $\lambda=100$ are directly determined from the analytical solution given in the Appendix. These values are presented in Table 1.

To demonstrate the applicability of the critical slip field method to the bearing capacity problem, a comparison of values of $N_{\gamma}$ for $\lambda=0$ with other solutions is given in Table 2. It can be seen that the values of $N_{\gamma}$ presently calcu-
Fig. 4. A typical passive critical slip field. $p_{p}$, passive earth pressure.

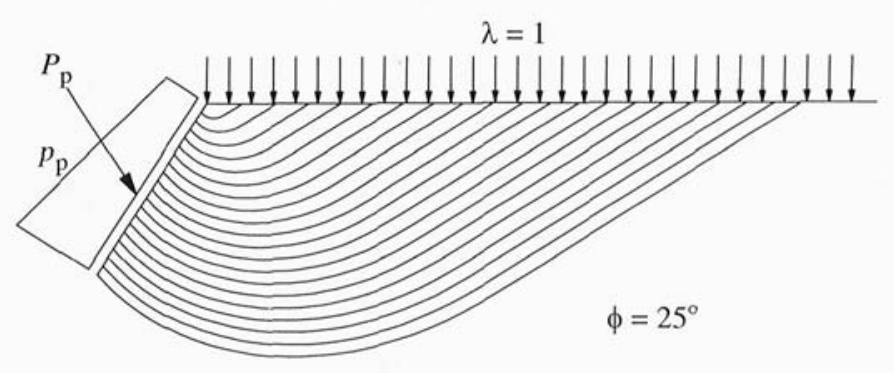

Fig. 5. Critical failure surfaces associated with different surcharge ratios.

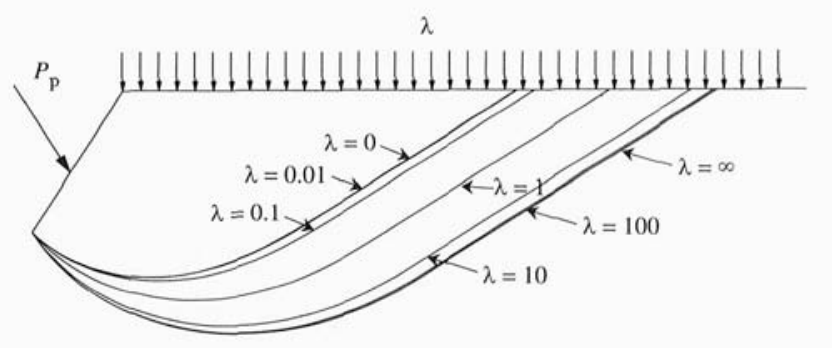

lated are smaller than those of Bolton and Lau (1993) by $10 \%$ or less, for $\phi$ in the range of $20-50^{\circ}$. For $\phi<20^{\circ}$ the term containing $N_{\gamma}$ plays a minor role in the sum of contributions to the bearing capacity. Thus the difference in values of $N_{\gamma}$ given from various sources may be of no practical significance. The differences between the present solutions and those of Vesic (1973) are considerably smaller except for $\phi>$ $45^{\circ}$, when the discrepancy reaches $12-20 \%$. This probably results from the conservative approximation made in Vesic (1973). The differences among the present solutions and those of Meyerhof (1963); Hansen (1970); and Chen (1975) are also evident in Table 2.

To further investigate the relationship between $N_{\gamma}$ and $\lambda$, we re-examine the computation results given in Michalowski (1997) based on a limit analysis. Bearing capacity factors $N_{c}, N_{\mathrm{q}}$, and $N_{\gamma}$ for various values of $q / \gamma B$ and $c / \gamma B$ and for $\phi=35^{\circ}$, as cited in Michalowski (1997), are shown in Table 3 of this paper and sorted according to the value of $\lambda$. To bring the bearing capacity factors into the same context as the present study, the factors $N_{\mathrm{c}}$ and $N_{\mathrm{g}}$ are restricted herein to their theoretical values from the Prandtl solution. The equivalent values of $N_{\gamma}$, which yield identical total bearing capacity values as Michalowski (1997), are also given in Table 3 . Values of the surcharge ratio $\lambda$ are calculated for various combinations of $c / \gamma B$ and $q / \gamma B$. Table 3 indicates that, for a given $\phi_{3} N_{\gamma}$ is related to $\lambda$. This also verifies the general existence of the equivalence of bearing capacity problems, as postulated in this paper, unrelated to the specific method used to calculate bearing capacity (such as limit analysis or the limit equilibrium method).

\section{Evaluation of error margins of the superposition assumption}

As noted previously, the bearing capacity factor $N_{\gamma}$ increases with the surcharge ratio $\lambda$ if no superposition as- 
Table 1. Numerical values of $N_{\gamma}$ and resultant errors in ultimate bearing capacity.

\begin{tabular}{|c|c|c|c|c|c|c|c|}
\hline \multirow[t]{2}{*}{$\lambda$} & \multirow[t]{2}{*}{$N_{\gamma}$} & \multicolumn{6}{|l|}{$\varepsilon(\%)$} \\
\hline & & $\begin{array}{l}\text { Present } \\
\text { modified }\end{array}$ & $\begin{array}{l}\text { Present } \\
\text { unmodified }\end{array}$ & $\begin{array}{l}\text { Vesic } \\
1973 \\
\end{array}$ & $\begin{array}{l}\text { Meyerhof } \\
1963\end{array}$ & $\begin{array}{l}\text { Hansen } \\
1970\end{array}$ & $\begin{array}{l}\text { Chen } \\
1975\end{array}$ \\
\hline \multicolumn{8}{|l|}{$\phi=5^{\circ}$} \\
\hline 0.00 & 0.38 & 0.0 & 0.0 & 18.4 & -81.6 & -78.9 & 23.7 \\
\hline 0.01 & 0.38 & 0.0 & 0.0 & 17.9 & -79.3 & -76.7 & 23.0 \\
\hline 0.10 & 0.40 & -0.3 & -3.9 & 9.7 & -58.4 & -62.2 & 13.6 \\
\hline 1.00 & 0.44 & -0.1 & -3.8 & 0.6 & -23.4 & -22.8 & 1.9 \\
\hline 10.00 & 0.47 & 0.4 & -0.8 & -0.1 & -3.4 & -3.3 & 0.0 \\
\hline 100.00 & 0.49 & 0.0 & -0.1 & 0.0 & -0.4 & -0.4 & 0.0 \\
\hline \multicolumn{8}{|l|}{$\phi=10^{\circ}$} \\
\hline 0.00 & 1.11 & 0.0 & 0.0 & 9.9 & -65.8 & -64.9 & 18.0 \\
\hline 0.01 & 1.12 & -0.8 & -0.8 & 8.7 & -64.4 & -63.5 & 16.5 \\
\hline 0.10 & 1.16 & -0.4 & -3.4 & 4.1 & -53.6 & -53.0 & 10.3 \\
\hline 1.00 & 1.30 & -0.2 & -4.5 & 1.9 & -18.6 & -21.4 & 0.2 \\
\hline 10.00 & 1.41 & 0.3 & -1.0 & 0.6 & -3.3 & -3.3 & -0.3 \\
\hline 100.00 & 1.45 & 0.0 & -0.1 & 0.0 & -0.4 & -0.4 & 0.0 \\
\hline \multicolumn{8}{|l|}{$\phi=15^{\circ}$} \\
\hline 0.00 & 2.52 & 0.0 & 0.0 & 5.2 & -55.2 & -53.2 & 16.7 \\
\hline 0.01 & 2.53 & -0.4 & -0.4 & 4.6 & -54.1 & -52.1 & 15.8 \\
\hline 0.10 & 2.63 & -0.5 & -3.4 & 0.6 & -46.6 & -45.1 & 9.6 \\
\hline 1.00 & 2.95 & -0.4 & -4.9 & -3.4 & -20.6 & -20.0 & -0.1 \\
\hline 10.00 & 3.23 & 0.3 & -1.1 & -0.9 & -3.4 & -3.3 & -0.5 \\
\hline 100.00 & 3.28 & 0.0 & -0.1 & -0.1 & -0.4 & -0.4 & 0.0 \\
\hline \multicolumn{8}{|l|}{$\phi=20^{\circ}$} \\
\hline 0.00 & 5.27 & 0.0 & 0.0 & 2.3 & -45.5 & -44.0 & 17.6 \\
\hline 0.01 & 5.30 & -0.6 & -0.6 & 1.7 & -44.9 & -43.5 & 16.6 \\
\hline 0.10 & 5.51 & -0.5 & -3.6 & -1.8 & -40.1 & -38.8 & 10.5 \\
\hline 1.00 & 6.18 & -0.4 & -5.4 & -4.6 & -19.5 & -19.0 & 0.1 \\
\hline 10.00 & 6.83 & 0.3 & -1.4 & -1.3 & -3.4 & -3.4 & -0.5 \\
\hline 100.00 & 6.91 & 0.0 & -0.2 & -0.1 & -0.4 & -0.4 & 0.0 \\
\hline \multicolumn{8}{|l|}{$\phi=25^{\circ}$} \\
\hline 0.00 & 10.85 & 0.0 & 0.0 & 0.3 & -37.7 & -37.7 & 19.4 \\
\hline 0.01 & 10.91 & -0.6 & -0.6 & -0.3 & -37.4 & -37.4 & 18.5 \\
\hline 0.10 & 11.34 & -0.5 & -3.7 & -3.7 & -34.5 & -34.5 & 12.4 \\
\hline 1.00 & 12.74 & -0.4 & -5.9 & -5.8 & -18.6 & -18.6 & 0.7 \\
\hline 10.00 & 14.14 & 0.3 & -1.6 & -1.6 & -3.6 & -3.6 & -0.6 \\
\hline 100.00 & 14.33 & 0.0 & -0.2 & -0.2 & -0.4 & -0.4 & 0.0 \\
\hline \multicolumn{8}{|l|}{$\phi=\mathbf{3 0}^{\circ}$} \\
\hline 0.00 & 22.75 & 0.0 & 0.0 & -1.5 & -31.1 & -33.8 & 21.6 \\
\hline $0.0 \mathrm{I}$ & 22.90 & -0.6 & -0.6 & -2.2 & -31.1 & -33.7 & 20.5 \\
\hline 0.10 & 23.77 & -0.4 & -3.7 & -5.0 & -29.7 & -31.9 & 14.3 \\
\hline 1.00 & 26.72 & -0.5 & -6.4 & -7.0 & -18.0 & -18.9 & 1.5 \\
\hline 10.00 & 29.79 & 0.3 & -1.9 & -2.0 & -3.7 & -3.9 & -0.6 \\
\hline 100.00 & 30.38 & 0.0 & -0.2 & -0.2 & -0.4 & -0.4 & -0.1 \\
\hline \multicolumn{8}{|l|}{$\phi=35^{\circ}$} \\
\hline 0.00 & 49.98 & 0.0 & 0.0 & -3.9 & -25.7 & -32.1 & 23.0 \\
\hline 0.01 & 50.29 & -0.6 & -0.6 & -4.4 & -25.7 & -32.1 & 21.9 \\
\hline 0.10 & 52.16 & -0.3 & -3.7 & -7.0 & -25.6 & -31.1 & 15.9 \\
\hline 1.00 & 58.70 & -0.6 & -7.1 & -8.7 & -17.5 & -20.1 & 2.2 \\
\hline 10.00 & 65.61 & 0.3 & -2.2 & -2.5 & -4.0 & -4.5 & -0.6 \\
\hline 100.00 & 67.74 & 0.0 & -0.3 & -0.3 & -0.5 & -0.5 & 0.0 \\
\hline \multicolumn{8}{|l|}{$\phi=40^{\circ}$} \\
\hline 0.00 & 118.18 & 0.0 & 0.0 & -7.4 & -20.7 & -32.7 & 22.9 \\
\hline 0.01 & 118.88 & -0.6 & -0.6 & -7.9 & -20.9 & -32.7 & 21.9 \\
\hline 0.10 & 123.23 & -0.2 & -3.7 & -10.2 & -21.7 & -32.2 & 16.2 \\
\hline 1.00 & 138.82 & -0.7 & -7.8 & -11.1 & -17.0 & -22.3 & 2.4 \\
\hline
\end{tabular}


Table 1 (concluded).

\begin{tabular}{|c|c|c|c|c|c|c|c|}
\hline \multirow[t]{2}{*}{$\lambda$} & \multirow[t]{2}{*}{$N_{\gamma}$} & \multicolumn{6}{|l|}{$\varepsilon(\%)$} \\
\hline & & $\begin{array}{l}\text { Present } \\
\text { modified }\end{array}$ & $\begin{array}{l}\text { Present } \\
\text { unmodified }\end{array}$ & $\begin{array}{l}\text { Vesic } \\
1973\end{array}$ & $\begin{array}{l}\text { Meyerhof } \\
1963\end{array}$ & $\begin{array}{l}\text { Hansen } \\
1970\end{array}$ & $\begin{array}{l}\text { Chen } \\
1975\end{array}$ \\
\hline 10.00 & 156.79 & $0 . \overline{3}$ & -2.7 & -3.3 & -4.4 & -.5 .4 & -0.8 \\
\hline 100.00 & 163.50 & 0.0 & -0.4 & -0.4 & -0.5 & -0.7 & 0.0 \\
\hline \multicolumn{8}{|l|}{$\phi=45^{\circ}$} \\
\hline 0.00 & 311.94 & 0.0 & 0.0 & -12.9 & -15.7 & -35.6 & 19.9 \\
\hline 0.01 & 313.72 & -0.6 & -0.6 & -13.3 & -16.1 & -35.6 & 19.1 \\
\hline 0.10 & 324.70 & -0.1 & -3.6 & -16.8 & -17.6 & -35.2 & 14.0 \\
\hline 1.00 & 366.19 & -0.7 & -8.6 & -14.7 & -16.1 & -25.7 & 1.2 \\
\hline 10.00 & 418.54 & 0.2 & -3.4 & -4.7 & -5.0 & -7.0 & -1.4 \\
\hline 100.00 & 442.74 & -0.1 & -0.5 & -0.6 & -0.7 & -0.9 & $-(0.2$ \\
\hline \multicolumn{8}{|l|}{$\phi=50^{\circ}$} \\
\hline 0.00 & 963.26 & 0.0 & 0.0 & -20.8 & -9.3 & -41.0 & 13.0 \\
\hline 0.01 & 968.76 & -0.6 & -0.6 & -21.1 & -9.7 & -41.0 & 12.5 \\
\hline 0.10 & 1001.07 & 0.1 & -3.6 & -22.4 & -12.5 & -40.6 & 8.3 \\
\hline 1.00 & 1126.93 & -0.5 & -9.3 & -20.7 & -14.3 & -31.7 & -2.1 \\
\hline 10.00 & 1316.69 & -0.1 & -4.6 & -7.2 & -5.8 & -9.7 & -2.9 \\
\hline 100.00 & 1412.67 & -0.2 & -0.7 & -1.0 & -0.8 & -1.3 & -0.5 \\
\hline
\end{tabular}

Table 2. Comparison of $N_{\gamma}$ values for $\lambda=0$.

\begin{tabular}{|c|c|c|c|c|c|c|}
\hline$\phi\left(^{\circ}\right)$ & Present & $\begin{array}{l}\text { Bolton and } \\
\text { Lau } 1993\end{array}$ & $\begin{array}{l}\text { Vesic } \\
1973^{a}\end{array}$ & $\begin{array}{l}\text { Meyerhof } \\
1963^{b}\end{array}$ & $\begin{array}{l}\text { Hansen } \\
1970^{\circ}\end{array}$ & $\begin{array}{l}\text { Chen } \\
1975^{d}\end{array}$ \\
\hline 5 & 0.38 & 0.62 & 0.45 & 0.07 & 0.08 & 0.47 \\
\hline 10 & 1.11 & 1.71 & 1.22 & 0.38 & 0.39 & 1.31 \\
\hline 15 & 2.52 & 3.17 & 2.65 & 1.13 & 1.18 & 2.94 \\
\hline 20 & 5.27 & 5.97 & 5.39 & 2.87 & 2.95 & 6.20 \\
\hline 25 & 10.85 & 11.6 & 10.88 & 6.77 & 6.76 & 12.96 \\
\hline 30 & 22.75 & 23.6 & 22.40 & 15.67 & 15.07 & 27.66 \\
\hline 35 & 49.98 & 51.0 & 48.03 & 37.15 & 33.92 & 61.47 \\
\hline 40 & 118.18 & 121.0 & 109.41 & 93.69 & 79.54 & 145.19 \\
\hline 45 & 311.94 & 324.0 & 271.74 & 262.74 & 200.81 & 374.02 \\
\hline 50 & 963.26 & 1052.0 & 762.85 & 873.84 & 568.56 & 1089.46 \\
\hline
\end{tabular}

Table 3. Re-examination of bearing capacity factors given in Michalowski (1997), for $\phi=35^{\circ}$.

\begin{tabular}{|c|c|c|c|c|c|c|c|c|}
\hline \multirow[b]{2}{*}{$\lambda$} & \multirow[b]{2}{*}{$q / \gamma B$} & \multirow[b]{2}{*}{$c / \gamma B$} & \multicolumn{3}{|c|}{ Original values in Michalowski (1997) } & \multicolumn{3}{|c|}{ Equivalent values } \\
\hline & & & $N_{c}$ & $N_{\mathrm{q}}$ & $N_{\gamma}$ & $N_{\mathrm{c}}$ & $N_{\mathrm{u}}$ & $N_{\gamma}$ \\
\hline 0.000 & 0 & 0 & - & - & 48.681 & & & 48.681 \\
\hline 1.428 & 0 & 1 & 48.256 & - & 54.118 & & & 58.384 \\
\hline 2.000 & 2 & 0 & - & 34.338 & 55.647 & & & 59.815 \\
\hline 2.856 & 0 & 2 & 47.099 & - & 57.380 & 46.123 & 33.296 & 61.284 \\
\hline 3.428 & 2 & 1 & 46.897 & 33.838 & 58.271 & & & 61.987 \\
\hline 4.856 & 2 & 2 & 46.629 & 33.649 & 59.799 & & & 63.235 \\
\hline 7.140 & 0 & 5 & 46.420 & - & 61.482 & & & 64.452 \\
\hline 9.140 & 2 & 5 & 46.313 & 33.429 & 62.646 & & & 65.078 \\
\hline
\end{tabular}

Note: --, indicates data not available. 
Fig. 6. Curves of $N_{\gamma}$ modification coefficient versus surcharge ratio $\lambda$.

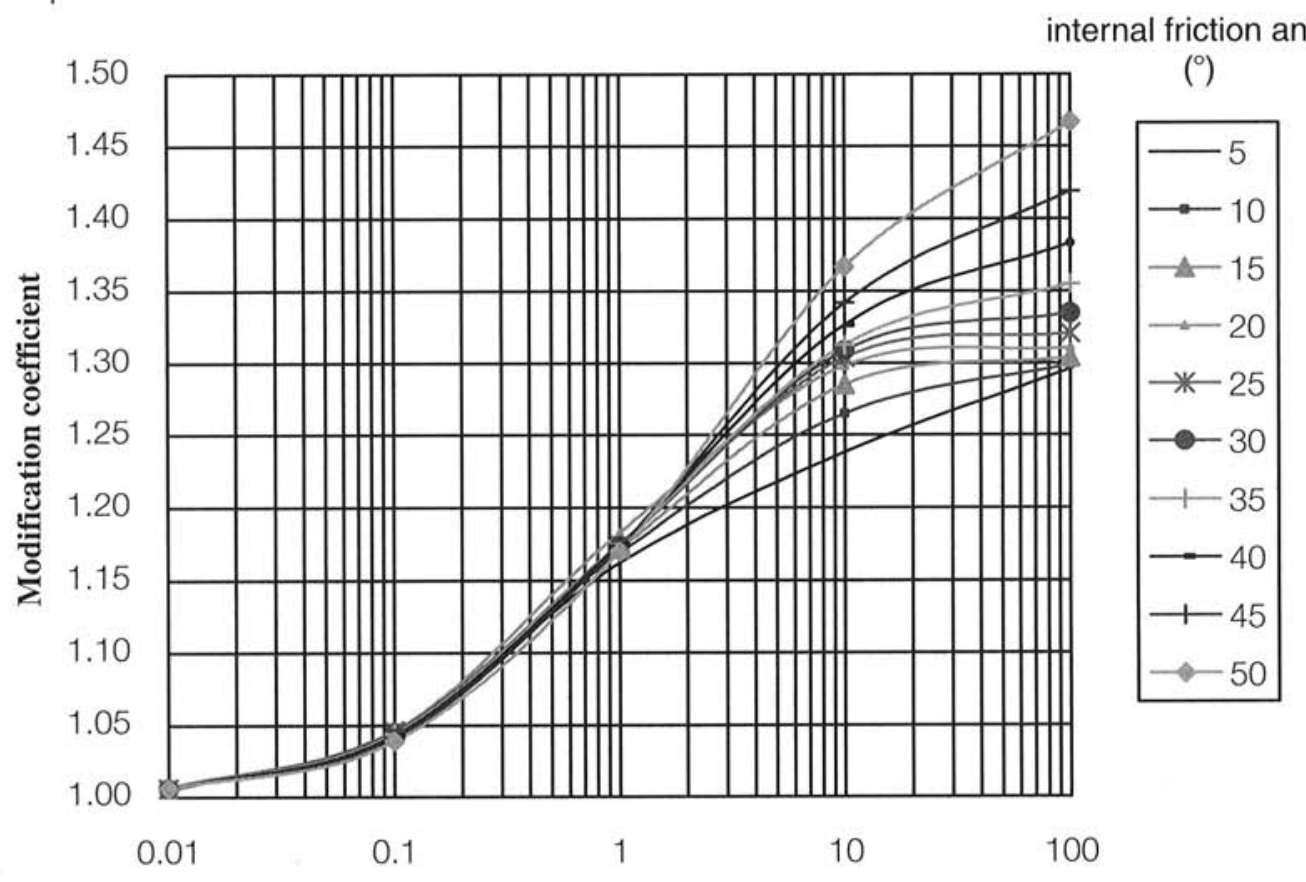

Surcharge ratio

sumption is made. At their limits, the values of $N_{\gamma}$ increase by $30-50 \%$ for a range of $\phi$ from 5 to $50^{\circ}$. However, this does not automatically imply that the total bearing capacity would be underestimated by the same degree when the superposition assumption is made. The exact degree by which the superposition assumption errs, along with its elimination, is of engineering interest.

Let $N_{\gamma}$ for the case of $\lambda=0$ be denoted as $N_{\gamma, \min }$ since it is the minimum value. Then $N_{\gamma}$ for the case of nonzero $\lambda$ can be represented by the product of a modification coefficient $\xi$ and $N_{\gamma, \mathrm{min}}$, that is:

$$
\xi=\frac{N_{\gamma}(\lambda)}{N_{\gamma, \min }}
$$

The numerical values of $\xi$ in Table 1 (not shown) are plotted graphically in Fig. 6. It can be seen in Fig. 6 that the internal friction angle has a negligible effect on $\xi$ when $\lambda$ is less than unity. For larger values of $\lambda$, the effect of the internal friction angle becomes more and more significant. At the same time, the contribution of $N_{\gamma}$ to the bearing capacity decreases. For practical use, a simple closed-form solution for the modification coefficient $\xi$ independent of the internal friction angle, is preferred as long as the error involved in the ultimate bearing capacity calculated (not $N_{\gamma}$ itself) is negligible. For this purpose, three approximate values of $N_{\gamma}$ applicable to all values of internal friction angle $(\xi=1.0$ when $\log _{10} \lambda=-2 ; \xi=1.04$ when $\log _{10} \lambda=-1$; and $\xi=1.16$ when $\left.\log _{10} \lambda=0\right)$ are chosen as a basis to form a Lagrangian interpolation function $\xi=0.04\left(\log _{k 0} \lambda+2\right)^{2}+1$.

The above equation is extended to the case of $\log _{10} \lambda=1$, or $\lambda=10$. For the case of $\lambda$ greater than $10, \xi$ is assumed to remain constant. Thus, the following approximate closedform solution for the modification coefficient $\xi$ is proposed for use in practice.
[14] $\xi= \begin{cases}1.0 & \text { for } \lambda \leq 0.01 \\ 0.04\left(\log _{10} \lambda+2\right)^{2}+1 & \text { for } 0.01<\lambda \leq 10 \\ 1.36 & \text { for } \lambda>10\end{cases}$

The error involved in the computation of the bearing capacity that results from the use of the approximate value of $N_{\gamma}$ is defined as

$$
\varepsilon=\frac{q_{\mathrm{u}}^{\text {approx }}-q_{\mathrm{u}}^{\text {exact }}}{q_{\mathrm{u}}^{\text {exact }}}
$$

where $q_{u}^{\text {approx }}$ represents the ultimate bearing capacity associated with the approximate values of $N_{\gamma}$, i.e., $N_{\gamma}^{\text {approx }}$, and $q_{u}^{\text {exact }}$ represents the ultimate bearing capacity associated with the exact values of $N_{\gamma}$ (denoted as $N_{\gamma}^{\text {cxact }}$ ) numerically computed without using the superposition assumption.

From eq. [3] it follows

$$
\text { [15] } \varepsilon=\frac{0.5\left(N_{\gamma}^{\text {approx }}-N_{\gamma}^{\text {exact }}\right)}{\lambda\left(N_{\mathrm{q}}-1\right)+\frac{q}{\gamma B}+0.5 N_{\gamma}^{\text {exact }}}
$$

For simplicity, the maximum value of $\varepsilon$ is adopted, that is

$$
\text { [16] } \varepsilon=\frac{0.5\left(N_{\gamma}^{\text {approx }}-N_{\gamma}^{\text {exact }}\right)}{\lambda\left(N_{\mathrm{q}}-1\right)+0.5 N_{\gamma}^{\text {exact }}}
$$

Values of $\varepsilon$ associated with the various sets of $N_{y}$ are listed in Table 1. It can be seen in Table 1 that the maximum error that results from conventional superposition approximation is up to $5-9 \%$ on the conservative side in most cases, being generally less than $10 \%$. Such an error margin is quite acceptable from the practical point of view since it is compatible with the error involved in determining the shear strength of soil. If eq. $[14\rfloor$ is used to modify $N_{\gamma}$, the crrors in the 
computed bearing capacity will be less than $0.7 \%$ on the safe side and less than $0.4 \%$ on the unsafe side.

Assuming that the present numerical values of $N_{\gamma}$ are "exact", the errors associated with the use of the $N_{\gamma}$-equations proposed by Vesic (1973), Meyerhof (1963), Hansen (1970), and Chen (1975) are determined and presented in Table 1. Because of the large differences in values of $N_{\gamma}$ among these solutions, the resultant errors are as much as $45 \%$ on the conservative side and $22 \%$ on the unsafe side for $\phi$ in the range of $20-50^{\circ}$, beyond which larger errors could occur. However, when the surcharge ratio $\lambda$ is greater than unity, the maximum errors would be less than $10 \%$ when using Vesic's equation and 20\% when using Meyerhof's or Hansen's equation, decreasing rapidly with the increase of $\lambda$ With Chen's equations, the errors in bearing capacity would become practically insignificant in the case of $\lambda>1$. In the case of a cohesionless soil, $\lambda>1$ represents the situation that the thickness of overburden is greater than the width of the foundation. In the case of frictional-cohesive soils, the corresponding overburden thickness would be shallower. Therefore, it can be tentatively concluded for most shallow foundations, the differences in ultimate bearing capacity resulting from the use of these well-known values of $N_{\gamma}$ would be no greater than $20 \%$. This suggest that the use of conventional procedures to compute the bearing capacity of shallow footings is justified from a practical point of view, given the many uncertainties involved in the acquisition of soil strength parameters and the large factors of safety commonly adopted in practice.

\section{Conclusion}

The bearing capacity of shallow foundations is conventionally determined using the superposition method. The exact solution without superposition approximation can still be expressed by the Terzaghi equation of bearing capacity, with the provision that the bearing capacity $N_{\gamma}$, is dependent on the surcharge ratio and the internal friction angle. Values of $N_{\gamma}$ without superposition approximation are numerically calculated using the critical slip field method. It is found that $N_{\gamma}$ increases with an increase in the surcharge ratio, approaching a limit as the surcharge ratio exceeds 100 . It is also found that the error in bearing capacity that results from the use of the superposition method is less than $10 \%$ on the safe side, which is quite acceptable from the practical standpoint. An approximate closed-form solution for the modification coefficient is proposed herein to modify the conventionally used $N_{\gamma}$, thus reducing the errors in bearing capacity calculations to less than $0.7 \%$ on the conservative side and less than $0.4 \%$ on the unsafe side. The errors in bearing capacity involved in some commonly used $N_{\gamma}$ equations are discussed, and for most practical problems, the maximum error would be around $20 \%$. The use of conventional procedures appears to be justified, but the inherent errors should be borne in mind when interpreting the causes of foundation failures or predicting the performance of foundations.

\section{Acknowledgement}

This study was financially supported by the Jockey Club Research and Information Center for Landslip Prevention and Land Development, at the University of Hong Kong. This support is gratefully acknowledged.

\section{References}

Bolton, M.D., and Lau, C.K. 1993. Vertical bearing capacity factors for circular and strips on Mohr-Coulomb soil. Canadian Geotechnical Journal, 30: 1024-1033.

Bellman, R. 1957. Dynamic programming. Princeton University Press, Princeton, N.J.

Chen, W.F. 1975. Limit analysis and soil plasticity. Elsevier, Amsterdam

Cox, A.D. 1962. Axially symmetrical plastic deformation in soils II Indentation of ponderable soils. International Journal of Mechanical Sciences, 4: 371-380.

Das, B.M. 1999. Shallow foundations: bearing capacity and settlement. CRC Press, Boca Raton, Fla.

Davis, E.H., and Booker J.R. 1971. The bearing capacity of strip footings from the standpoint of plasticity theory. In Proceedings of the 1st Australian - New Zealand Conference on Geomechanics, Melbourne, pp. 276-282.

De Beer, E.E., and Vesic, A. 1958. Etude experimentale de la capacite portante du sable sous des foundations directes etablics en surface. Annales des Travaux Publics de Belgique, 59(3): 5-88.

Hansen, J.B. 1970. A revised and extended formula for bearing calpacity. Danish Geotechnical Institute, Copenhagen, Bulletin, 28: $5-11$.

Lundgren, H., and Mortensen, K. 1953. Determination by the theory of plasticity of the bearing capacity of continuous footings on sand. In Proceedings of the 3rd International Conference on Soil Mechanics and Foundation Engineering (ICSMFE), Zurich, Vol. 1, pp. 409-412.

Meyerhof, G.G. 1963. Some recent research on the bearing capacity of foundations. Canadian Geotechnical Journal, 1: 16-31.

Michalowski, R.L. 1997. An estimate of the influence of soil weight on bearing capacity using limit analysis. Soils and Foundations, 37(4): 57-64.

Powrie, W. 1997. Soil mechanics: concepts and applications. E \& FN Spon, London, U.K.

Sieffert, J.-G., and Bay-Gress, Ch. 2000. Comparison of European bearing capacity calculation methods for shallow foundations. Geotechnical Engineering, Institution of Civil Engineers, 143: 64-74.

Sokolovskii, V.V. 1965. Statics of granular media. Pergamon Press, New York.

Terzaghi, K. 1943. Theoretical soil mechanics. 5th ed., John Wiley \& Sons Inc., New York, N.Y.

Vesic, A.S. 1973. Analysis of ultimate loads of shallow foundations. Journal of the Soil Mechanics Foundations Division, ASCE, 99(1): 45-73.

Vesic, A.S. 1975. Foundation Engineering Handbook. Ist ed., Edited by H.F. Winterkorn and H.-Y. Fang. Van Nostrand Reinhold, Chapter 3.

Xiao, D.P, Zhu, W.Y., and Chen, H. 1998. Progress in slip lines method to solve the bearing capacity. Chinese Journal of Geotechnical Engineering, 20(4): 25-29. In Chinese.|

Zhu, D.Y., Qian Q.H., and Lee, C.F. 2001. Active and passive critical slip fields for cohesionless soils and calculation of lateral earth pressures. Géotechnique, 51(5): 407-423.

\section{Appendix A: Derivation of $\boldsymbol{N}_{\gamma}$ for the case of $\lambda=\infty$}

The failure surface in the case of $\lambda=\infty$ is a combination 
Fig. A1. Derivation of $N_{\gamma}$ for the case of $\lambda=\infty$.

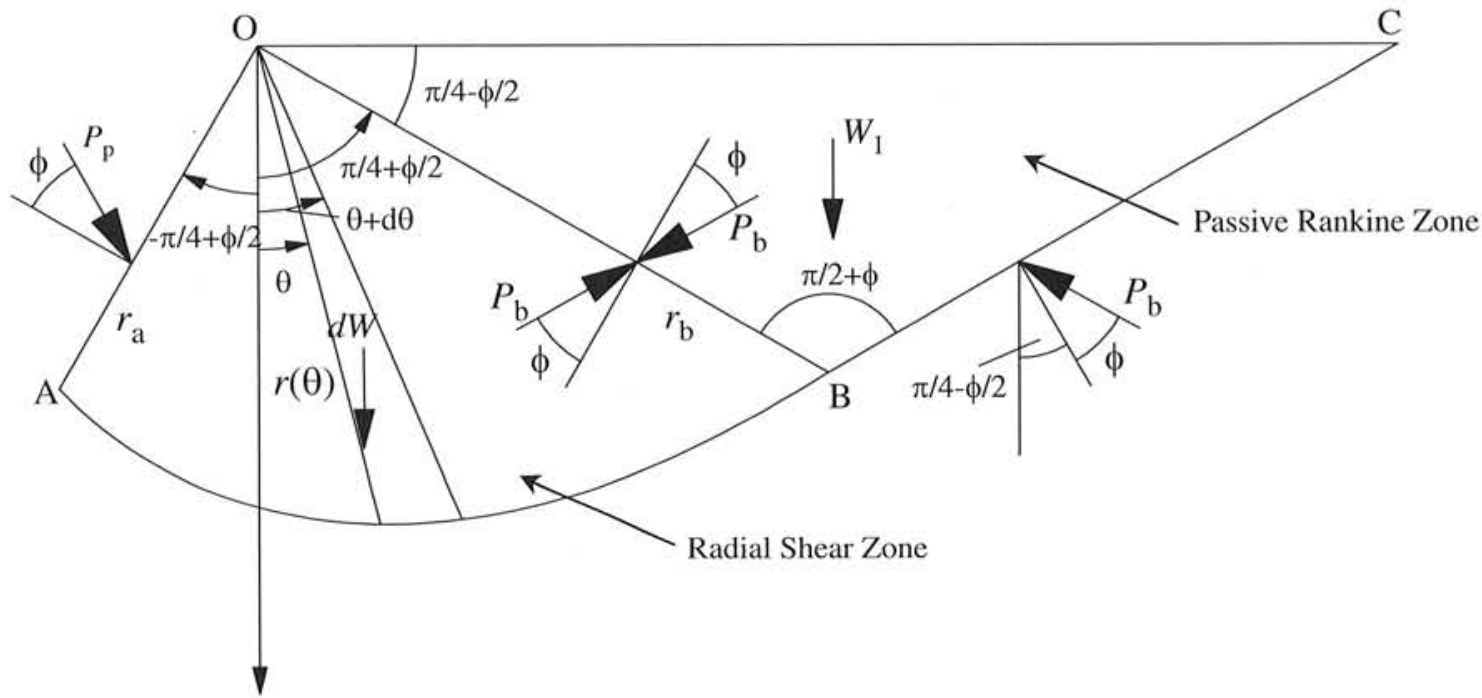

of a straight line and a log-spiral as shown in Fig. A1. The failure region can be divided into the passive Rankine zone and the radial shear zone. The failure surface bounding the radial shear zone is described by

[A1] $r(\theta)=r_{\mathrm{a}} \mathrm{e}^{\theta+\frac{\pi}{4}-\frac{\phi}{2} \tan \phi}$

where $\theta$ is the angular coordinate shown in Fig. A1, and $r_{\mathrm{a}}$ is the length of OA. Taking the breadth of the footing and the self-weight of the soil as unity, we have

$$
\begin{aligned}
& N_{\gamma}=4 P_{\mathrm{p}} \cos \left(\frac{\pi}{4}-\frac{\phi}{2}\right)-\frac{1}{2} \tan \left(\frac{\pi}{4}+\frac{\phi}{2}\right) \\
& r_{\mathrm{a}}=\frac{1}{2 \sin \left(\frac{\pi}{4}-\frac{\phi}{2}\right)}
\end{aligned}
$$

The length of the edge of the passive Rankine zone is

[A4] $r_{\mathrm{b}}=r_{\mathrm{a}} \mathrm{e}^{\frac{\pi}{2} \tan \phi}$

The weight of the passive Rankine zone is

$$
W_{1}=\frac{1}{2} r_{\mathrm{b}}{ }^{2} \cos \phi=2 P_{\mathrm{b}} \cos \left(\frac{\pi}{4}+\frac{\phi}{2}\right)
$$

From vertical equilibrium of the passive Rankine zone, the force acting on the edge $\mathrm{OB}$ is derived as follows:

$$
P_{\mathrm{b}}=\frac{1}{2} r_{\mathrm{b}}^{2} \cos \left(\frac{\pi}{4}-\frac{\phi}{2}\right)
$$

The point of action of $P_{\mathrm{b}}$ lies at the lower third point of OB. Taking the moment of $P_{\mathrm{b}}$ about point $\mathrm{O}$ (moment being positive when taken in clockwise rotation),

$$
M\left(P_{\mathrm{b}}\right)=\frac{2}{3} P_{\mathrm{b}} r_{\mathrm{b}} \cos \phi
$$

Substituting $P_{\mathrm{b}}$ from eq. [A5] and $r_{\mathrm{b}}$ from eq. [A4], the above equation becomes
[A6] $M\left(P_{\mathrm{b}}\right)=\frac{1}{3} r_{\mathrm{a}}{ }^{3} \mathrm{e}^{1.5 \pi \tan \phi} \cos \phi \cos \left(\frac{\pi}{4}-\frac{\phi}{2}\right)$

Now determine the moment of weight of the radial shear zone about point $\mathrm{O}$, i.e., $M(W)$. Selecting an infinitesimal slice with a weight of $\mathrm{d} W$ as shown in Fig. 6

$$
\mathrm{d} W=\frac{1}{2} r^{2} \mathrm{~d} \theta
$$

Herein, $\mathrm{d} W$ is acting at the lower third point of the infinitesimal slice. Then taking the moment of $\mathrm{d} W$ about point $\mathrm{O}$

$$
\mathrm{d} M=\frac{1}{2} r^{2} \frac{2}{3} r \sin \theta \mathrm{d} \theta
$$

and integrating over the whole radial shear zone yields

$$
M(W)=\frac{1}{3} r_{\mathrm{a}}{ }^{2} \mathrm{e}^{\left(\frac{\pi}{4}-\frac{\phi}{2}\right) 3 \tan \phi} \int_{-\frac{\pi}{4}+\frac{\phi}{2}}^{\frac{\pi}{4}+\frac{\phi}{2}} \sin \theta \mathrm{e}^{3 \tan \phi \cdot \theta} \mathrm{d} \theta
$$

Integrating the above equation gives

$$
\begin{aligned}
& M(W)=\frac{1}{3(1+9}\left.\tan ^{2} \phi\right) \\
& r_{\mathrm{a}}{ }^{2} \mathrm{e}^{\frac{\pi}{4}-\frac{\phi}{2} 3 \tan \phi} \\
& \times\left[(3 \tan \phi \sin \theta-\cos \theta) \mathrm{e}^{3 \tan \phi \cdot \theta}\right] \frac{\pi}{4}+\frac{\pi}{2}+\frac{\phi}{2}
\end{aligned}
$$

Taking the moment of the earth force $P_{\mathrm{p}}$ about point $\mathrm{O}$ and noting that its point of action lies at the lower third point,

[A8] $M\left(P_{\mathrm{p}}\right)=-\frac{2}{3} r_{\mathrm{a}} P_{\mathrm{p}} \cos \phi$

From moment equilibrium of the radial shear zone

$$
M\left(P_{\mathrm{b}}\right)+M(W)+M\left(P_{\mathrm{p}}\right)=0
$$


The earth force $P_{\mathrm{p}}$ can be expressed as

[A9] $P_{\mathrm{p}}=\frac{3}{2 r_{\mathrm{a}} \cos \phi}\left[M\left(P_{\mathrm{b}}\right)+M(W)\right]$

Let

$$
\mu=\frac{\pi}{4}-\frac{\phi}{2} \quad f=\tan \phi
$$

Substituting eqs. [A6] and [A7] into eq. [A9] and then into eq. [A2], the bearing capacity factor $N_{\gamma}$ for the case $\lambda=$ $\infty$ is analytically obtained as

$$
\text { [A10] } N_{\gamma}=\frac{\mathrm{e}^{1.5 \pi f}}{2 \tan ^{2} \mu}-\frac{1}{2 \tan \mu}
$$

$$
\begin{array}{r}
+\frac{\mathrm{e}^{3 \mu f}}{4 \sin ^{3} \mu\left(1+9 f^{2}\right)}\left[(3 f \cos \mu-\sin \mu) \mathrm{e}^{3 f(\mu+\phi)}\right. \\
\left.+(3 f \sin \mu+\cos \mu) \mathrm{e}^{-3 f \mu}\right]
\end{array}
$$

